\title{
Sor Juana y Nicolás de Cusa
}

\section{Sor Juana and Nicholas of Cusa}

\section{Rocío Olivares Zorrilla}

Universidad Nacional Autónoma de México

MÉXICO

rocio52@prodigy.net.mx

[Hipogrifo, (issn: 2328-1308), 2.2, 2014, pp. 107-125]

Recibido: 15-05-2014 / Aceptado: 10-06-2014

DOI: http://dx.doi.org/10.13035/H.2014.02.02.08

Resumen. Sin contemplar la extraordinaria y consistente impronta del pensamiento de Nicolás de Cusa en la obra de Sor Juana Inés de la Cruz, difícilmente se llegará a una comprensión profunda de una de las escritoras más relevantes del Barroco iberoamericano. La herencia del cusano destinó a Sor Juana el símbolo de las pirámides contrapuestas de luz y sombra y la metáfora del círculo y el centro ya tamizada por los místicos peninsulares. Ambos símbolos de su Primero sueño se inscriben en el cambio de episteme renacentista que significó la versión óptica y matemática de las ideas siempre a partir de la explicación de sí mismo, de uno mismo como parte de un universo circular, esférico, cuyo ojo central y omnivisivo podemos ver descrito en diversas obras del cusano. La idea de la contemplación divina con los ojos materiales cerrados, pues lo incorpóreo solo es accesible deslindándose de lo corpóreo; las especulaciones matemático-geométricas sobre lo divino y la concepción del mundo como un conjunto de signos; el modo como lo infinito se encuentra en lo finito y el conocimiento del mundo como probabilidad y conjetura, todo esto son destellos de pensamiento que iluminan el Primero sueño, una de los poemas más intelectuales e inquietantes de la literatura hispánica.

Palabras clave. Sor Juana Inés de la Cruz, Nicolás de Cusa, filosofía, teología, símbolos, poesía, contemplación, conocimiento, pirámides, círculo, centro, divinidad.

Abstract. Without evaluating the extraordinary and consistent impression that Nicholas of Cusa exerted on the works by Sor Juana Inés de la Cruz, it would be hardly possible to achieve a profound comprehension of one of the most prominent women writers of the Latin American Baroque period. The Cusan's legacy provided Sor Juana with the symbol of the opposing pyramids of light and shadow, and with the metaphor of the circle and the center, already sifted by the Spanish mystics. Both symbols in her poem The Dream inscribe within a Renaissance change of episteme, in which a mathematical and optical version of the ideas was always produced through the elucidation of oneself, of the individual as part of a cyclic, spherical universe in which a central, all-seeing eye is described in various works by Nicholas of Cusa. The idea of divine contemplation with our bodily eyes closed, for 
the incorporeal is only accessible by getting rid of the corporeal; the mathematical and geometrical speculations about divinity and the conceptions of the world as a combination of signs; how the infinite and the finite encounter and the knowledge of the world is always a probability and a conjecture, all these are philosophical traces which enlighten The Dream, one of the most captivating intellectual poems in Spanish literature.

Keywords. Sor Juana Inés de la Cruz, Nicholas of Cusa, Philosophy, Theology, Symbols, Poetry, Contemplation, Knowledge, Pyramids, Circle, Center, Divinity.

Sin reconocer la consistente presencia del pensamiento de Nicolás de Cusa en la obra de Sor Juana Inés de la Cruz, difícilmente se llegará a una comprensión profunda de una de las figuras más significativas del Barroco hispánico. Igualmente, no llegaremos a caracterizar con fidelidad toda una época en la cultura iberoamericana sin tener en cuenta la profunda huella de las disquisiciones metafísicas y teologales de Nicolás de Cusa. Su legado, ya evidente en las diversas escuelas místicas en la España del siglo XVI y sus secuelas en el siglo siguiente, destinó a Sor Juana la representación de las pirámides contrapuestas de luz y sombra y la metáfora del círculo y el centro ya tamizada por los místicos peninsulares. Ambos símbolos de su Primero sueño se inscriben en el cambio de episteme renacentista que significó la versión óptica y matemática de las ideas siempre a partir de la explicación de sí mismo, de uno mismo como parte de un universo circular, esférico, cuyo ojo divino, central y omnivisivo, es perfilado en diversas obras del Cusano, ya en De docta ignorantia, ya en De conjecturis, en De ludo globi o en De visione Dei. La teología negativa de raigambre neoplatónica; la idea de la contemplación divina con los ojos materiales cerrados, pues lo incorpóreo sólo es accesible deslindándose de lo corpóreo; las especulaciones matemático-geométricas sobre lo divino y la concepción del mundo como un conjunto de signos; el modo como lo infinito se encuentra en lo finito y el conocimiento del mundo como probabilidad y conjetura, todo ello son destellos de pensamiento que iluminan el Primero sueño, una de los poemas intelectuales más incitantes de la literatura hispánica.

Sirva, nuevamente ${ }^{1}$, para abrir una justa restitución a Nicolás de Cusa el origen de este y otros símbolos presentes en la obra de Sor Juana, el caso de las encontradas pirámides de luz y sombra, cuyas respectivas penetraciones una en otra simbolizan la manifestación de lo divino en lo material y humano y la divinización de lo humano. Es preciso insistir en que este influjo concreto de Nicolás de Cusa en el Primero sueño pone en entredicho la atribución a Athanasius Kircher $^{2}$ que Karl $V_{\text {Vossler }}{ }^{3}$ hizo de este símbolo y, con ello, la supuesta fuente kircheriana de Sor Juana a este respecto. Con ello, es preciso revisar también la reproducción que otros

1. En diversas ocasiones he mencionado esta cuestión en la interpretación del Primero sueño, sin que nadie más se hubiese percatado antes del precedente de Nicolás de Cusa. Citaré la fuente de todas ellas: Olivares, 1998a. Ver también Olivares, 1998b; 2001; 2004a, y 2004b.

2. Vossler da las supuestas fuentes de esta imagen: Kircher, Oedipus Aegyptiacus, pp. 110 y ss., y Obelisci aegyptiacus nuper..., pp. 20 y ss.

3. Juana Inés de la Cruz, Obras completas, I, pp. 79-81. 
han hecho de esta atribución de Vossler a Kircher, desde Octavio Paz hasta la crítica aficionada posterior que solemos escuchar en coloquios y congresos. Lo que podemos apreciar en la crítica más prestigiada de la obra de Sor Juana, al menos hasta los años ochenta ${ }^{4}$, Alfonso Méndez Plancarte ${ }^{5}$, Octavio Paz ${ }^{6}$ y Marie-Cécile Benassy ${ }^{7}$, es que Cusa es mencionado, sobre todo, respecto a la metáfora del círculo divino, aunque también, por Méndez Plancarte y por Benassy, en relación con la idea del hombre como microcosmos. Ninguno de ellos menciona alguna otra obra de Nicolás de Cusa y todos aceptan la referencia a Kircher de Vossler ${ }^{8}$. No obstante, Benassy revela mayor conocimiento de los planteamientos e implicaciones del De docta ignorantia y aborda, aunque sea muy brevemente, la filiación de Sor Juana con Cusa9. Nadie, sin embargo, se percató de dos cuestiones fundamentales: la primera, que la metáfora del círculo era ya un lugar común en la literatura mística no sólo europea, sino concretamente hispánica ${ }^{10}$; la segunda es que la alusión al símbolo de las pirámides encontradas de luz y sombra viene de Nicolás de Cusa.

Resulta por demás curioso que, al aceptar sin más la fuente aducida de Vossler, con ella acepten la filiación de dicha metáfora con el hermetismo. Es decir, que con ello se «asimila» por los críticos de Sor Juana que el origen de este símbolo está en Jámblico, en el Corpus hermeticum, en el alquimista andaluz Artefio, en el cabalista Maimónides y en el propio Zoroastro, puesto que estas son las únicas fuentes del símbolo que Kircher cita en su comentario sobre las pirámides de luz y sombra'11.

4. Omito la obra de Sabat de Rivers, 1977 a, quien no menciona a Nicolás de Cusa en ningún momento.

5. Notas al «Primero sueño», en Juana Inés de la Cruz, Obras completas, l, pp. 575-603.

6. Paz, 1982.

7. Benassy, 1983.

8. Méndez Plancarte, 1951, p. 594; Paz, 1982, pp. 485-486; Benassy, 1983, pp. 141-142. A este respecto, Sabat de Rivers también apoya extensamente y hasta con entusiasmo el parecer de Karl Vossler (por ejemplo, confiriendo a Kircher también el origen de la figura de Harpócrates, que italianos, franceses e ingleses del Renacimiento, por no nombrar a los españoles, solían invocar desde el siglo XVI en textos de diversa índole), 1977a, pp. 17, 73, 106, 114, 137.

9. Benassy, 1983, pp. 147-148, donde atribuye a Cusa la idea del hombre como microcosmos en el Primero sueño. La realidad es que Sor Juana tenía un sinfín de fuentes más en este tema específico que la de Nicolás de Cusa.

10. Ver Olivares, 1998a, pp. 80-81, nota 156, donde contextualizo el tópico tal como aparece en Sor Juana en relación con Francisco de Aldana, Pedro de Encinas, Lope de Vega y Alonso de Bonilla. Esta observación forma parte del avance publicado en 1998b, pp. 198-199, n. 22; también en 2004a, pp. 490, n. 11. De todos estos precedentes, quizá el que más patentemente antecede a Sor Juana en relación con la geometría divina es Francisco de Aldana, como podemos ver, además de los versos citados de las Siete octavas a Dios, estos de la «Carta para Arias Montano sobre la Contemplación de Dos y los Requisitos della», en Aldana, 1985, p. 441, vv. 85-90: «...cual pece dentro el vaso alto, estupendo, / del oceano irá su pensamiento / desde Dios para Dios yendo y viniendo. / Serále allí quietud el movimiento, / cual círculo mental sobre el divino / centro, glorioso origen del contento».

11. Kircher, Obeliscus Pamphilius, pp. 170-171. Estos mismos comentarios los publica Kircher después en Oedipus Aegyptiacus, pp. 110-113. 

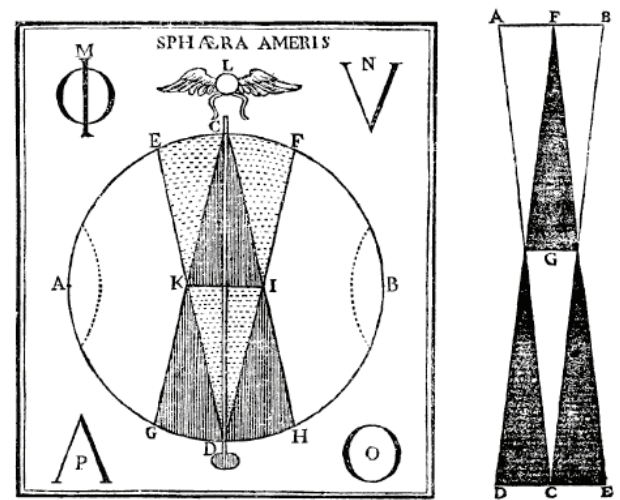

Imagen 1. Athanasius Kircher en Oedipus Aegyptiacus:

diagrama de las pirámides encontradas de luz y sombra.

Insisto, es extraño que la crítica contemporánea no haya comentado esto, sobre todo cuando la mera mención del influjo de un autor cristiano, cardenal notable y conocidísimo por todas las órdenes religiosas desde el siglo XV llega a despertar en algunos dudas o reticencias ${ }^{12}$. No obstante, al dar por «indudable» ${ }^{13}$ el origen kicheriano de este símbolo, se llevan con el bocado todo el contexto zodiacal y daimónico en el que Kircher coloca su descripción de las dos pirámides. ¿Será porque la crítica sólo ha limitado a repetir lo dicho por Karl Vossler sin recurrir a las fuentes citadas? Así parece, pues en ellas podemos apreciar, sea en el Oedipus Aegyptiacus, sea en el Obelisci..., que Kircher, siguiendo su personal programa, tiene toda la intención de ofrecer la arqueología hermética del símbolo de las pirámides presente en el pensamiento cristiano. Si bien es cierto que el Asclepio contiene esta idea de la ida y regreso de los elementos hacia su existencia vital en el mundo inferior o hacia su fuente en el mundo superior, aunque sin mencionar proyecciones piramidales o cónicas, hay otras fuentes neoplatónicas más plausibles y otros posibles precedentes en el pensamiento no cristiano, como sería Proclo, para quien el proceso de la creación $-y$, por ende, del conocimiento, en sentido contrario- es una emanación progresiva de luz ${ }^{14}$. Proclo es ampliamente recuperado por el Pseudo Dionisio, por el propio Nicolás de Cusa y por Marsilio Ficino, cuyas respectivas actualizaciones de los neoplatónicos griegos cristianos y paganos ejercieron su correspondiente influjo en el pensamiento renacentista y barroco ${ }^{15}$. Por otra parte,

12. Sorprende, por ejemplo, que Marie-Cécile Benassy se mire mucho la punta de los zapatos cuando incursiona en la «posible» influencia de Nicolás de Cusa en Sor Juana. Ver Benassy, 1983, p. 109.

13. Méndez Plancarte, en Juana Inés de la Cruz, 1951, p. 594.

14. Proclus, pp. 30-31: «Platon n'a pas dit que le feu est seul à être visible: ce serait là doublement une erreur. Car le feu pris à lui seul, sans mélange avec les autres éléments, n'est nullement objet de vue, on en a seulement le concept, et en outre aucune des autres réalités ne sera visible si le feu est seul à être visible. (...) D'où l'on peut conclure que tous les corps participent du feu, mais que le feu est autre pour tel et tel objet. Car la lumière n'est pas même chose que la flamme, ni la flamme que la braise, mais il se fait, depuis le haut jusqu'à la terre, une dégradation du feu, lequel procède de plus immatériel, plus pur et plus incorporel jusqu'aux cops les plus immergés dans la matière et les plus épais».

15. Copenhaver, 1992, p. 149. 
la alusión al cabalismo hispano, como el de Maimónides, en el Renacimiento español no resultaría tan descabellada, de no ser porque Kircher sólo refiere a él una idea que está presente en muchos neoplatónicos: que cuanto más se desembaraza del mundo terrenal, el alma se vuelve más luminosa. No obstante, el Zoroastro que cita Kircher (probablemente el mismo Proclo, comentador de los Oráculos caldeos adjudicados por Giorgios Gemistos Pleton a Zoroastro ${ }^{16}$ ) y el alquimista Artefio parecen estar fuera del contexto de Sor Juana. La supuesta fuente kircheriana de las pirámides de luz y sombra del Primero sueño queda, desde una perspectiva más amplia, muy debilitada frente al influjo que pudo ejercer sobre Sor Juana la obra de Nicolás de Cusa.

Independientemente de su origen, la formulación más acabada del símbolo en cuestión, desde el punto de vista de la filosofía y teología cristianas, es la del Cusano, cuya obra se difundió ampliamente, como he dicho, a partir de la invención de la imprenta. Su texto en De coniecturis dice a la letra:

Haz progresar una pirámide de luz en las tinieblas y una pirámide de tinieblas en la luz, y podrás convertir en conjetura todo lo investigable así reducido a figura, como una conducción manual de lo sensible a lo arcano. Apoyado en el ejemplo, contempla el mundo representado en esta figura que lo imita. Advierte que Dios, que es la unidad, es como el fundamento de luz: pero el fundamento de la tiniebla es como la nada ${ }^{17}$.

El alcance anagógico de este símbolo es que representa a la vez cómo la creación procede de lo uno y el desprendimiento humano del «dominio de los sentidos», así como su acercamiento al arcano creador donde están todas las razones germinales de lo creado. Cabe precisar que la alusión a este símbolo en el Primero sueño de Sor Juana no es literal, sino paradigmática, es decir, no corresponde de manera directa a lo dicho en los versos constitutivos del poema, sino que se sitúa en el plano contextual y se desprende tanto del contenido discursivo del poema como de una estructuración general fincada en la mención -en lo que es propiamente ya el nivel semántico y elocutivo del texto- de la sombra de la noche al principio y la luz del sol al final. Dicha estructuración responde, por lo demás, a los modelos de la silva latina y la italiana, de las que forma parte importante la descripción de los movimientos de la naturaleza, como son la sucesión de la noche y el día o la de las estaciones del año. Los ejemplos peninsulares de este asunto abundan, desde las octavas de Arjona hasta las silvas de Quevedo ${ }^{18}$. Aunque no es este nuestro tema ahora, habrá que decir que los precedentes clásicos y renacentistas de El sueño de Sor Juana también suelen ser soslayados por la crítica en general -con la notable, aunque no

16. Burns, 2006, pp. 158-179

17. «Facque pyramidem lucis in tenebras et tenebrae pyramidem in lucem progredi, et omne inquisibile in figuram redigito, ut sensibili manuductione ad arcana coniecturam convertere possis. Et ut in exemplo allevieris, universum in eam figuram hic subtus conspice redactum. Adverte quoniam deus, qui est unitas, est quasi basis lucis; basis vero tenebrae est ut nihil». Nicolás de Cusa, De coniecturis, Pars prima, cap. IX. Ver Olivares 2009, p. 151, donde me refiero por primera vez a la edición digitalizada del texto de Cusa, ya citado en Olivares, 1998a, p. 33, de la edición de Nicolás de Cusa, Opera, p. 84. 18. Egido, 1989, pp. 12-13, 18-19. 
exhaustiva, excepción de Georgina Sabat de Rivers ${ }^{19}-$ y, con ellos, los antecedentes europeos de Ronsard y Spenser ${ }^{20}$. Lejos de pasar por alto a estos poetas europeos, más valiera percatarnos de que su cultivo de los mismos temas nos viene a iluminar la lectura del Primero sueño. Habría que señalar, por ejemplo, la importante presencia del Eclesiastés en la preocupación constante de Ronsard por los ciclos de la naturaleza, su ir y venir perpetuo y regulado por la divinidad. En cuanto a Spenser, su inclinación al alegorismo y no a la anagogía lo equipara a la noche del Primero sueño tal como es representada al final del poema. Para él, la Noche es una deidad infernal, la abuela universal; negros caballos arrastran su carro y ella es la fuente del mal. Como un reflejo de toda esta personificación, lo que leemos al final del poema de Sor Juana es solamente la huida de la Noche con sus huestes de sombra hacia el otro hemisferio. En Spenser la Noche trata de aniquilar a los hijos del Día, aunque ellos terminan sometiéndola, de manera muy parecida a como la vemos al final de El sueño; en The Faerie Queene, además, la Noche y el Día se enfrentan en cada crepúsculo luciendo sendos mantos, uno carmesí y el otro gris. De cualquier modo, en otros contextos poéticos la noche y el día son parte del orden divino y desaparece entonces la caracterización siniestra de aquella. Este es el comportamiento peculiar de los tópicos en los textos literarios y nos muestra claramente cómo la representación de la noche como una villana se vuelve una alegoría en franca vía hacia la lexicalización, sin ninguna pretensión anagógica; sin embargo, precisamente porque la instauración de su Primero sueño en la sucesión de la noche y el día no es elocutiva sino simbólica, Sor Juana impulsa al lector a buscar una explicación más allá de lo meramente alegórico en la sombra nocturna que abre el poema y sirve de fondo al sueño del alma, es decir, una razón metafísica, justo como Cusa la desarrolla en su Ars coniecturalis ${ }^{21}$. De tal suerte nos queda claro que, al soslayar la fuente de Nicolás de Cusa, permanecemos ajenos ya no digamos al tópico de los ciclos naturales de la Antigüedad al Renacimiento, sino a las sutilezas de la razón ontológica que se desprende de la referencia, por un lado, a la noche en la que tendrá origen el sueño revelador del alma y, por otro, al día que restituye el orden real de la creación. En el primer caso, la sombra piramidal de la noche prefigura la elevación del alma humana a su máxima potencia desde la materialidad de su cuerpo dormido; en el segundo, la luz del sol cierra categóricamente tanto el sueño de la protagonista como el poema mismo con una evidente carga de optimismo fáctico que descansa en la generosidad y justicia divinas manifiestas en el mundo creado. También debemos observar que este final luminoso no ha presentado ninguna controversia en su interpretación y que esto responde más bien a su evidente referencia cósmica, universalmente reconocida como el fin de los sueños nocturnos -hecho que Sor Juana representa según el usus scribendi de otros poetas de su tiempo, es decir, alegorizando los elementos naturales como sendas figuras antropomóficas: los rayos del sol como «tropas bisoñas», las sombras de la noche como «negros escuadrones», la luz del sol como la del «padre» y la noche como una «funesta tirana», todo ello dramatizado con ataques de florete de las primeras luces, retrocesos y tropiezos de las sombras y embestidas

19. Sabat de Rivers, 1977b, pp. 763-775

20. Hamilton, 1990, p. 511.

21. Otro título dado a la misma obra: De coniecturis. 
de mil luces doradas de la madeja solar-. Este desenlace del poema como una lucha militar corresponde, como vemos, al contexto de la alegorización que la poesía del Renacimiento suele hacer de los fenómenos cósmicos, la cual incluso puede tener en algunos casos un aspecto jocoso, muy a tono en este caso con la figura cálida y alegre del sol22. También debemos subrayar la diferencia de tonos al principio y al final del poema: la modulación épica de la alegoría del advenimiento del día, a diferencia de la inflexión enigmática y simbólica, cargado de melancolía, de la sombra nocturna en la obertura del anochecer. Ésta última vertiente es menos frecuente en la semiosis de la poesía renacentista, pero también existe y va por derroteros filosóficos que no toca la primera vertiente, anecdótica y teatral. Podemos encontrarla, por ejemplo, en la poesía isabelina, como en George Chapman, Michael Drayton o William Browne ${ }^{23}$, quienes representan a la noche como el espacio privilegiado de la meditación melancólica y, por ende, del recogimiento contemplativo. Aun así, hay que reconocer la superioridad del poema de Sor Juana con respecto a sus paralelos europeos. Esa atmósfera que invita a la contemplación y elevación es justamente el aura que envuelve a la pirámide de sombra nocturna al principio de El sueño; ese será espacio que permitirá al poema y a su protagonista, el alma humana, realizar una travesía no sólo cognoscitiva, sino espiritualmente trascendente, la cual eleva del plano alegórico al anagógico a la pirámide de sombra que inaugura el poema. Es la sombra nocturna, en fin, el espacio en el que sobreviene el prodigio del sueño, así como en la oscuridad el teólogo negativo se aproxima a la majestad divina. Muy lejos estamos de las noches congestionadas de pecadores y ladrones en el poema de Sor Juana y muy cerca del silencio y quietud de La noche oscura del alma, de San Juan de la Cruz.

Volviendo a Cusa, la fecundidad de su propuesta en De coniecturis alimenta la literatura mística y filosófica posterior. La pirámide de sombra adquiere en su concepción una tesitura ontológica y esencial, cuya complementariedad con la pirámide de luz forma parte del plan divino de la creación. Quizá uno de los ejemplos más ricos sea el De umbris idearum, de Giordano Bruno ${ }^{24}$. En esta obra Bruno postula, al igual que Cusa, Boecio y la propia teoría pitagórica, que el orden del universo está dado por números y que, por tanto, la visión humana sólo puede tolerar una manifestación oscurecida de la divinidad, la cual se atempera mediante la sombra al separarse en las diferentes especies creadas. A esto llama Bruno «sombras ideales» ${ }^{25}$. En diversas partes de la obra de Bruno es identificable esta teología negativa bajo la cual él afirma que sólo con los ojos y la boca cerrados puede el místico acercarse a Dios ${ }^{26}$. Son Nicolás de Cusa y el Pseudo Dionisio quienes inspiran a Bruno. Él mismo menciona a los «príncipes platónicos» como su fuente, y los estudiosos han identificado también los resabios del Timeo, del Asclepio, de la Teología platónica de Ficino y de Pico de la

22. Ver «Las estaciones del día», en Salazar y Torres, Cythara de Apolo, pp. 67-70, donde la Aurora, vestida al desgaire y con el cabello mal atado, sale a barrer de madrugada como una moza, la Luna se apea, trasnochada, de su carro, el Sol se acerca en el suyo y la Noche se va llorando a las antípodas. 23. Hamilton, 1990, p. 511: «In Chapman (The Shadow of Night 1594), Drayton (Endymion and Phoebe 1595, and The Owle 1604), and William Browne (Britannia's Pastorals 3.1.335-697)».

24. Brunus Nolanus, De umbris idearum.

25. Bruno, Las sombras de las ideas, Intenciones tercera C, cuarta D y quinta E, pp. 40-41.

26. Bruno, Los heroicos furores, libro II, diálogo IV, p. 214. 
Mirándola ${ }^{27}$, quien también describe a Dios como el abismo incognoscible del ensoph cabalístico en sus Conclusiones. Bruno presenta, así, un pequeño diagrama en el cual aparece un cono de sombra desprendiéndose de la tierra, del cual explica cómo las sombras se unen para integrar una sola que se eleva a la mente divina.

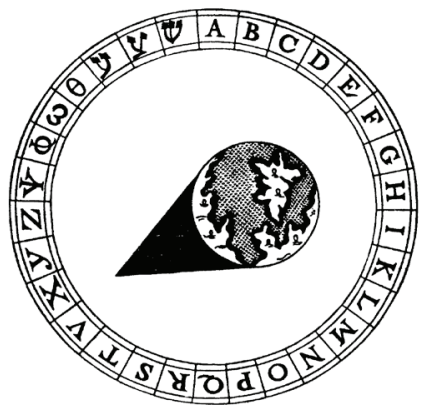

Imagen 2. Giordano Bruno, De umbris idearum elevación de la pirámide de sombra de las especies inteligibles.

Igualmente, en su Libro del ascenso y descenso, Raymundo Lulio expuso esta idea neoplatónica que luego Nicolás de Cusa formuló con los términos de explicación y complicación, como un sístole y diástole, y que representó con el entrecruzamiento de las pirámides de luz y sombra. En algunas ediciones aparece el diagrama correspondiente, donde la base de la pirámide luminosa es la unidad y la base de la pirámide de sombra es la alteridad, transitando ambas, de ida y de vuelta, del primer al tercer cielo y del ínfimo mundo al supremo.

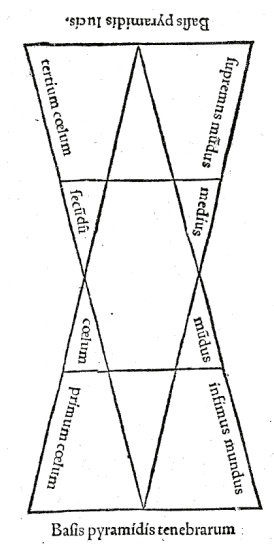

Imagen 3. Nicolás de Cusa, De coniecturis: pirámides encontradas de luz y sombra. 
El planteamiento de Cusa está íntimamente relacionado con otra metáfora que a través de su De docta ignorantia tuvo gran difusión en el mundo cristiano: la metáfora de Dios como un círculo infinito. Ha sido ya muy comentado cómo Sor Juana favorece esta figura del círculo en todas sus obras importantes: en el Primero sueño no sólo aparece anagógicamente al mencionar el círculo divino de Nicolás de Cusa, sino también cuando alude a la vigilancia siempre renovada de todo los que llevan una corona ${ }^{28}$. En el Neptuno alegórico, Sor Juana abre su texto con el jeroglífico «egipcio» de Dios como un círculo ${ }^{29}$. En la Respuesta a Sor Filotea vuelven a aparecer la metáfora de Cusa y la alusión a la mejor de todas las coronas: la obsidional, que simboliza el triunfo de Cristo sobre las acechanzas del demonio ${ }^{30}$. De hecho, en la tradición cristiana ya estaba presente la metáfora del círculo divino en los Soliloquios de San Agustín ${ }^{31}$ y, luego, en la Consolación de la filosofía, de Boecio $^{32}$. Además, tal parece que el antecedente más remoto es la esfera de Empédocles $^{33}$. Si Sor Juana menciona la obra Magnes ${ }^{34}$, de Kircher, como referencia, no significa que ella desconozca los precedentes cristianos. Más aún, el jesuita alemán coloca su comentario acerca de la esfera infinita como corolario de un libro enteramente dedicado a la descripción científica de las fuerzas magnéticas del mundo. En cambio, la cita que de ella hace Sor Juana en el Primero sueño revela que tenía al lado la obra de Cusa, pues toda la reflexión del Cusano gira en torno a la relación entre la curva y la recta al pensar en un círculo infinito, algo inexistente en el libro de Kircher. En la Respuesta, la enunciación no deja ver claramente estos elementos discursivos, pues se trata de una expresión muy sintética de la idea; en El sueño, por el contrario, tenemos el elemento de la línea recta que normalmente no aparece en la transmisión de esta metáfora mística. Veamos la versión en la Respuesta a Sor Filotea:

Todas las cosas salen de Dios, que es el centro a un tiempo y la circunferencia de donde salen y donde paran todas las líneas criadas ${ }^{35}$.

Esto es, más o menos, lo que dice Kircher en el capítulo final de su libro, constituido por teoremas y experimentos físicos. Ahora comparemos la fórmula de la Respuesta con la del Primero sueño:

\footnotetext{
28. Juana Inés de la Cruz, Obras completas, I, pp. 338-338, vv. 141-146.

29. Juana Inés de la Cruz, Obras completas, IV, p. 355, II. 1-6.

30. Juana Inés de la Cruz, Obras completas, IV, pp. 455-456, II. 628-675.

31. Agustín de Hipona, Soliloquiorum libri duo.

32. Boecio, Tratados teológicos y la Consolación de la filosofía, libro V, prosa 6, pp. 202-206.

33. Ver el uso de la metáfora en la obra conservada del filósofo presocrático: «Empedokles of Akragas», frags. 27-36, en Burnet, 1920.

34. Kircher, Magnes, sive de arte magnética opus tripartitum.

35. Juana Inés de la Cruz, «Respuesta a Sor Filotea», en Obras completas, IV, p. 450, II; pp. 421-424. El lugar citado es Kircher, Magnes, sive de arte magnética opus tripartitum, p. 790: «Megacosmicos cum admiratione intuitus ex Nihil igitur porro estat, nisi ut explicatis singulis ad totius Magnetice actionis fontem, totius concatenationis nostrae nexum \& vinculum ad Aeternum illum, inquam, \& universae naturae Magnetem centralem, a quo sicut per divinam radiorum diffusionem omnia emanarunt, ita ad eam veluri ad amoris universi centrum \& Magnetem ravт' revertamur».
} 


\begin{abstract}
...que como sube en piramidal punta
al Cielo la ambiciosa llama ardiente,

así la humana mente

su figura trasunta,

y a la Causa Primera siempre aspira,

- céntrico punto donde recta tira

la línea, si ya no circunferencia,

que contiene, infinita, toda esencia- ${ }^{36}$.
\end{abstract}

Si observamos bien, ambos fragmentos comparten la idea del centro (Dios, Causa Primera) y la circunferencia infinita, pero la línea recta sólo aparece en los versos del Primero sueño. Al parecer, nadie ha reparado en este detalle, que tiene una singular importancia filosófica y teológica. ¿Qué papel juega aquí la línea recta? El asunto no aparece por ningún lado en el contexto de la cita del libro de Kircher, en cambio forma parte esencial del planteamiento del Cusano, quien en De docta ignorantia sostiene con un rico discurso y con un diagrama la famosa paradoja. En él, especula sobre la naturaleza curva de la línea recta y sobre la máxima rectitud de la circunferencia menos curva, es decir, la circunferencia infinita:

Ahora bien, en primer lugar, que sea recta la línea infınita es patente: el diámetro del círculo es una línea recta, y la circunferencia es una línea curva mayor que el diámetro. Si, por lo tanto, la línea curva recibe menos en su curvatura, resulta que la circunferencia sería de un círculo mayor; por tanto la circunferencia del círculo máximo, la cual no puede ser mayor, es mínimamente curva. Por lo cual es máximamente recta ${ }^{37}$.

Precisamente porque la infinitud tiene en sí todas las formas, es igual que lo que contiene en sí todas las esencias sea una recta, un punto o una circunferencia. El reflejo de la línea recta en el Primero sueño queda perfectamente explicado, lo que nunca sucedería si nos atuviésemos sólo a Kircher. Cusa plantea que la máxima circunferencia es máximamente recta en cualquiera de sus lados, así como la mínima circunferencia es mínimamente recta. Si la circunferencia divina es infinita, es igual a la línea recta, tanto como su centro es igual a su circunferencia. Por tanto, la infinitud puede ser expresada por la igualdad de todas las figuras.

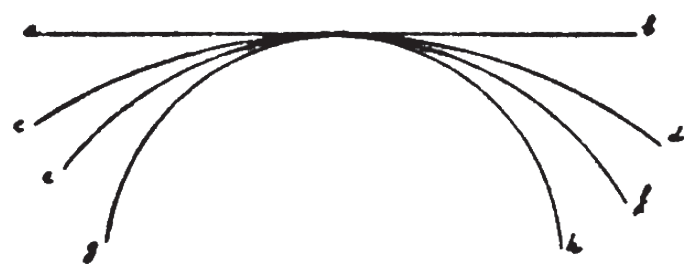

Imagen 4. Nicolás de Cusa, De docta ignorantia, la recta y el círculo. 
Pero lo que quizá sea más inquietante entre todos los paralelos entre Sor Juana y Nicolás de Cusa -y lo que no observaron nuestros tres críticos sorjuanistassea el considerar que toda probabilidad y conjetura del mundo finito, que nunca alcanza a completarse, esté firmemente ligada a otras probabilidades y conjeturas igualmente finitas, mientras la única actualidad de toda posibilidad es Dios. Pareciera que esta postura filosófica, en las postrimerías del siglo XVII de la América colonial, insistiese en la unidad de la diversidad. Así, desde la esencia de la fuente o de la rosa, en la explicación o despliegue del universo y unida a la esencia de todos los reinos y jerarquías que componen el mundo, sólo una máxima conexión con la esencia absoluta -aunque nunca se alcance- es lo que puede dar sentido a esa pluralidad. Más aún, la esencia de la fuente y la rosa y la de todo ente individual de la creación, por lo que tienen en sí de maravilloso y digno de asombro, contienen la infinitud de su primera causa. De tal modo, ninguna práctica religiosa finita es plena en sí misma para alcanzar el infinito ${ }^{38}$, así como ninguna cultura ni lengua finita alcanza la infinitud por sí misma; antes bien, sólo todas juntas pueden ofrecer un vislumbre de lo infinito o brillar en la más profunda oscuridad. Así sucede con las cosas que el alma contempla y con la propia alma soñante que finalmente despierta; así también sucede con la noche y el día mismos como parte de la totalidad. La infinitud divina conforma y modera a la vez los componentes de la creación. Por ello, el Dios de Cusa está más allá de todos los atributos que la conjetura humana pueda concebir: su inteligencia está más allá de todo atisbo de la inteligencia absoluta; su verdad supera todo aquello que puede ser considerado como la verdad más innegable; su luz desborda la más exultante luminosidad porque se vuelve oscuridad impenetrable por toda conjetura ${ }^{39}$. Mientras más se aproximan las conjeturas a su luz, más densas son las tinieblas divinas, porque Dios no es un ser como otro ser, sino el único ser absoluto. He aquí el discurso soterrado del Primero sueño, cuya atención esparcida en la mínima copiosidad de toda la creación se vuelca en la persecución, en la cacería ${ }^{40}$, de la máxima sabiduría.

La oscuridad es, pues, un presupuesto metafísico del poema de Sor Juana, con ella inicia en silencio y quietud y dentro de ella se gesta la experiencia de este saber sin saber, de este conocimiento que tropieza constantemente con los obstáculos de la propia finitud pero sin doblegar jamás su filiación divina ${ }^{41}$. El sueño, entonces, inicia en clave de «noche oscura del alma».

Es innegable todo lo que estos planteamientos le deben no sólo a Platón, sobre todo al Timeo, sino también a la Teología mística del Pseudo Dionisio ${ }^{42}$. A través de sus obras teológicas, Cusa siempre insta al lector a la empresa de la elevación teórica -es decir, espiritual- por las esferas concéntricas del universo. Otro concepto característico de Nicolás de Cusa, en efecto, es el de theosis o theoria, proveniente de la patrística griega, que Cusa debió aprender en los textos de Gregorio de Nisa,

38. Wind destaca este postulado de Cusa en De pace seu concordantia fidei en 1972, p. 221

39. Nicolás de Cusa, Acerca de la docta ignorancia, pp. 120-125.

40. Ver más adelante la presencia del De venatione sapientiae de Cusa en El Divino Narciso.

41. Ver también más adelante el parentesco de El Divino Narciso con De filiatione Dei, de Cusa.

42. Pseudo Dionisio, Teología mística, pp. 371-380. 
quien también lo hereda al Pseudo Dionisio ${ }^{43}$. La theosis es el corolario de las obras de Cusa. Significa la salvación y deificación del alma mística. La restitución del alma humana a su origen divino une así todos los contrarios: ser y no ser, luz y oscuridad, finitud e infinitud, pero con un sentido trascendente que parte de una nostalgia melancólica llena de deseo y que reclama una inquietud épica del intelecto nacida del recogimiento interior. Sea mediante las matemáticas o sea por la poesía, el trazo al infinito del alma humana es creativo y poético en el sentido de los furores o entusiasmos que Ficino reactualiza en el Renacimiento. En un momento dado, el filósofo alemán afirma:

Pero cuando deseo dirigirme hacia cosas incorpóreas, me aíslo de las cosas corpóreas y cuanto más ciertamente intento especular sobre estas cosas incorpóreas, más ciertamente me deslindo de las cosas corpóreas. Y cuando deseo contemplar mi alma, que no es un objeto de la visión sensible, la observo mejor con los ojos sensibles cerrados. Y hago del alma el instrumento para observar cosas incorpóreas. Cuando intento entender las disciplinas me remito al poder del entendimiento del alma ${ }^{44}$.

Los trasiegos del alma humana en su tesón cognoscitivo también desembocan, en el Primero sueño, en la creciente certeza de que las esencias de lo corpóreo son inasibles y que sólo «con los ojos sensibles cerrados», se puede arribar a la intuición de la suma total de las inasibles esencias de todo lo corpóreo, porque dicha suma, como totalidad, es incorpórea, aunque comprenda todo lo corpóreo. Esto es theoria en el sentido teológico, tal como la expresa Cusa en el fragmento anterior del De ludo globi. En El sueño, el método de las diez categorías le sirve al alma para percatarse de que con su aplicación no adquirirá el ansiado conocimiento de las cosas del mundo. Cusa, por su parte, propone la abstracción del alma:

Al faltar luz el ojo no puede ver nada, a pesar de ser un ojo sano. Así, el alma que carece de la luz manifiesta que es Cristo no puede ver, aun cuando sea incorrupta, ni puede vivir merced a la vida intelectual. Porque así como la visión sensible requiere de la luz sensible reveladora para que sea cierta y dotada de vida, así también la visión intelectual necesita de la vida intelectual de la verdad para ver o vivir. Y ya que todo número termina en denario, he imaginado el ascenso al décimo círculo -pasando por nueve de ellos- mismo que resulta ser un círculo que es un centro ${ }^{45}$.

Es así como los diez círculos de ascenso intelectual son la contraparte exacta de las diez categorías aristotélicas: éstas, vertidas sobre las cosas corpóreas; aquellos, progresando hacia el centro de la visión intelectual. Pero, ¿cuándo se llega a la contemplación directa de ese centro divino? Si no es por la contemplación de lo material, tampoco es en el ascenso intelectual, porque -he aquí la paradoja- mientras mayor es el ascenso hacia Dios, Dios se vuelve más oscuro. Entonces -en la cúspide de esa visión intelectual- es cuando Cusa exclama en De visione Dei: 
¡Oh rostro maravilloso, cuya belleza son incapaces de admirar aquellos que llegan a verla! El rostro de todos los rostros está velado en todos los rostros y sólo es visto en un enigma. No se encuentra desvelado hasta que uno ha penetrado, más allá de todas las visiones, en un estado de profundo silencio en el que no queda nada para imaginar o conocer un rostro. Porque en tanto que no se alcanza esa oscuridad, esa nube, esa negrura, es decir, esa ignorancia en que aquél que busca tu rostro entra cuando trasciende todo conocimiento y entendimiento, hasta entonces, tu rostro sólo puede alcanzarse velado. Esa misma oscuridad, sin embargo, demuestra que es en esa trascendencia de todos los velos donde se encuentra presente el rostro... Y cuanto más densamente se siente la oscuridad, más verdadero y cercano es el acercamiento - en virtud de esa oscuridad - a la invisible luz ${ }^{46}$.

Lo extraordinario y original del poema de Sor Juana es que en este sueño, inicialmente, la visión intelectual rebasa la potencia del ver onírico, atado a lo corpóreo, y es imposible de aprehender como tal la idea de todo lo creado; en un segundo momento, que la interrelación entre la razón y el intelecto, aparentemente la única vía abierta a la sed de saber, impide también - precisamente por un constante e irremisible remontarse de la observación a la intelección- que el alma soñante se dé por satisfecha con la relatividad del método creado por el hombre para conocer las cosas corpóreas. Sor Juana no sólo retoma a Cusa en muchos y variados de sus postulados, sino que los lleva al extremo y los pone en el juego mismo de la especulación filosófica a partir de un sueño concreto en que se nos presenta el ascenso espiritual a la vez como simulacro y como realidad. Con ello nos demuestra que no sólo puede entrar en el certamen de la poesía con la materia asimilada y mejorada que le han ofrecido sus contemporáneos, maestros y compañeros, sino que también puede investigar por su cuenta con el caudal discursivo de los teólogos, como Nicolás de Cusa. Habría que señalar, por lo demás, que esta empresa de Sor Juana equilibra y pone en función brillantemente el legado aristotélico-escolástico con el platónico y neoplatónico y todo ello en una filigrana poética ubérrima en dibujos, inflexiones y texturas.

Finalmente, habrá que señalar la fecundidad del pensamiento de Cusa en otra obra de Sor Juana: El Divino Narciso. El manejo de la fábula mitológica en la que se basa este auto sacramental es singular aun reconociendo todo lo que pueda deber a Calderón de la Barca, puesto que Sor Juana aquí, además de inspirarse en los textos de Nicolás de Cusa, propone mediante su auto no sólo que la religión cristiana contiene en sí lo mejor de las otras religiones, sino también que todas las religiones son un reflejo de la verdad divina. La propuesta es audaz porque podría entenderse la verdad cristiana como una más, pero no se sale un ápice de la ortodoxia. Sin decirlo a las claras, Sor Juana dispone de tal modo los elementos dramáticos

46. Nicolás de Cusa, Opera, cap. vi, «De visione faciali», pp.185-186. Ver Olivares, 1998a, p. 197, y 1998b, p. 192. Aquí habría que citar la observación de Cassirer sobre este pasaje de Cusa: «Cada ser particular e individual tiene una relación inmediata con Dios, se coloca ante Él como si fuese cara a cara. Pero el verdadero sentido de lo divino comienza por revelarse cuando la mente ya no permanece ante una de esas relaciones, ni siquiera ante la simple suma de todas, sino que las recoge todas en la unidad de una visión, la visio intellectualis», en Cassirer, 1963, 31-32. La traducción es mía. 
en su auto, que van llevando a la conclusión de que el Logos, la verdad revelada, por más clara que ofrezca la imagen de lo divino en su fundamental propuesta de amor, enfrenta a los cristianos al misterio infinito de esa misma verdad reflejada en sus enigmáticas manifestaciones, ya sean gozosas (la Encarnación), dolorosas (la Crucifixión) o gloriosas (la Resurrección). Por tanto, la religión cristiana resuelve en sí las conjeturas de la religión de los indios americanos o la de los antiguos griegos porque las contiene y unifica a todas en el mismo Logos, pero la religión cristiana también es una conjetura o aproximación a la verdad divina en la medida en que el intelecto humano no tiene en sí mismo una visión exacta de lo que hay detrás del misterio si no es en el propio Logos, siendo la fe en los misterios revelados el único modo de aproximación, por así decirlo, nouménica. El teólogo negativo de Cusa lo expresa así en De filiatione Dei o De la filiación divina:

Supongamos que el Dios glorioso es una elevada Imagen de nuestro Comienzo, una Imagen en la que aparece Dios Mismo. Llamemos a esta Imagen «Espejo de Verdad», sin mácula, completamente recta, absolutamente perfecta, sin defectos. Pensemos en todas las criaturas como espejos con diferentes grados de contracción y curvados diversamente. De estas criaturas, consideremos que sus naturalezas intelectuales son espejos vivientes, unos más planos y más claros en su imagen que otros. [...] Digo, entonces: una sola luz resplandece con diversidad en todos los espejos reflejantes. Pero en la resplandeciente imagen primera y la más perfecta de todas, los otros espejos aparecen tal y como son. [...] De tal modo, en ese primer Espejo, el Espejo de Verdad (como podemos llamar a la Palabra de Dios, al Logos, al Hijo), el espejo intelectual obtiene su filiación, de tal manera que todas las cosas están en todas las cosas, y todo está en él, su reino y su posesión, en la vida gloriosa de Dios y de todo lo creado ${ }^{47}$.

Es así como ante los ojos de «Occidente» y «América», los personajes de la loa, queda clara la justicia divina: el «Celo» que enarbola la espada por la «Religión» cristiana también es falible y puede distorsionar la verdad del Logos. Estas son las ideas que están en juego en El Divino Narciso, donde Narciso mismo es un espejo perfecto que se ve reflejado en toda naturaleza humana para la llenarla de gracia, y que refleja a toda naturaleza humana -en su máxima o mínima perfección- para redimirla.

En De venatione sapientiae o A la caza de la sabiduría, Nicolás de Cusa expone cómo el descenso del Intelecto Divino supone el ascenso del intelecto del hombre en la medida en que el hombre desea a Dios, de tal suerte que la cacería de lo deseado, de esa "Causa de todo deseo», culmina en la unión amorosa intelectual. Veamos un fragmento del texto de Cusa:

dado que lo uno y el ser de la naturaleza intelectual son ambos intelectuales, están firmemente enlazados en una unión intelectual. Pero la unión intelectual de amor no puede ni flaquear ni perecer, porque la sabiduría inmortal alimenta la actividad de la razón. Por consiguiente, la unión natural de la naturaleza intelectual -una 
naturaleza inclinada a la sabiduría- no sólo conserva la naturaleza intelectual con el fin de existir, sino que la adapta a lo que ama naturalmente, para que pueda unirse a lo que ama. Por lo tanto, el espíritu de la sabiduría desciende al espíritu del intelecto de acuerdo con el fervor del deseo -así como el deseado desciende al que desea- y dirige al espíritu del intelecto hacia sí mismo, unido a ese espíritu intelectual por amor. Como dice Dionisio, a semejanza del fuego asimila lo que se une a sí, y lo asimila según la aptitud de cada objeto asimilado. Y en esta unión de amor el intelecto encuentra la felicidad y vive felizmente ${ }^{48}$.

Tenemos, así, otro presupuesto filosófico ineludible para arribar a la más intrincada significación de El Divino Narciso y nos explicamos la motivación de Sor Juana para elegir a este personaje mitológico de Narciso, emblema de la autocontemplación. En el símbolo de la semejanza especular, llevado al terreno teológico, no sólo vio lo que ya habían expresado por su parte Plotino en la Antigüedad y Marsilio Ficino en el Renacimiento ${ }^{49}$, -esto es, la filiación divina a pesar del afecto del alma por el cuerpo y la insignificancia del reflejo del alma en el cuerpo material ante lo inconmensurable del reflejo divino en el hombre-, sino también una perspectiva omnisciente $y$, en términos afines al pensamiento de Cusa, omnivisiva, capaz de resolver de una sola mirada las profundas contradicciones del mundo moderno y la confrontación entre Europa y América. Sobra observar además lo perfectamente concatenado del pensamiento de Cusa en todas sus obras: así es como podemos vislumbrar también en estas propuestas las pirámides de luz y sombra descritas en De coniecturis. En El Divino Narciso, la naturaleza humana busca desde un inicio el perdón de Dios en la fuente del bautismo, y es la Gracia reencontrada quien le permite ahí un centelleo de Narciso; como al alma del místico, un primer vislumbre es suficiente para mantener una búsqueda perpetua de su centro divino, y en eso percibimos un paralelo con el Primero sueño, donde el alma -centrada en su intelecto- jamás es vencida en su denuedo por la máxima sabiduría. Esta determinación inquebrantable la describe Nicolás de Cusa en De venatione sapientiae de la siguiente manera:

la sabiduría es un vapor del poder de la majestad de Dios, un cazador [de la sabiduría] se maravilla ante la prístina y agradabilísima fragancia de este vapor -fragancia que refresca toda su capacidad intelectual. Y por esa fragancia se inflama con deseo indescriptible de apresurarse a aprehender la sabiduría de la que no duda estar cerca. Por esta gozosa esperanza el progreso del cazador se sostiene y acelera, pero aun así se retarda por la carga del cuerpo que lleva consigo ${ }^{50}$.

48. Nicolás de Cusa, «De venatione sapientiae», cap. 25 (73), p. 1324. La traducción al español es mía. 49. Ver Olivares, nov 2010 a feb 2011; las fuentes ahí citadas son: Plotino, Enéada cuarta, IV, 12, pp. 7677 (por errata, en el texto se menciona la Enéada III, aunque la referencia en la nota es correcta), y Ficino, De amore, Discurso Sexto, caps. XVII-XIX, pp. 177-186. En Plotino vemos la fábula del espejo de Dionisos traspuesta a las almas humanas que no se desprenden de Zeus a pesar de encarnar en su reflejo especular; en Ficino leemos sobre lo espurio del reflejo del alma humana en el cuerpo frente al sublime reflejo de amor entre Dios y su criatura.

50. Nicolás de Cusa, «De filiatione Dei», cap. 15 (45), p. 1306. La traducción es mía. 
Una vez más, la equiparación de ese invencible deseo no sólo hace consistente El Divino Narciso con el Primero sueño, sino también la correspondencia de ambas obras con las de Nicolás de Cusa, quien en De venatione sapientiae describe lo que ha dicho de otra manera en De docta ignorantia o en De filiatione Dei.

Más aún, la filosofía de Nicolás de Cusa le dio también a Sor Juana la pauta para hacernos ver cómo todos los reflejos imperfectos también se reflejan entre sí en el terreno intelectual de los conceptos. Es en ellos como expresamos nuestras semejanzas y nuestras diferencias, de manera más o menos aproximada, pero siempre en camino, en un proceso de mayor o menor concordancia entre opuestos que nunca termina porque el único espejo irreprochable -que resuelve en sí todos los reflejos opuestos- está más allá de todas las posibles geometrías de las especulaciones humanas.

Queda para otro momento reflexionar más a fondo sobre las muchas razones que inclinaron a Sor Juana a esta teología negativa de pasmosa sutileza. Baste ahora constatar que en relación con el conjunto de su obra, Nicolás de Cusa no puede ser más una mención de paso.

\section{BIBLIOGRAFÍA}

Agustín de Hipona, San, Soliloquiorum libri duo, I, 4-5 y II, 20, en Sant'Agostino. Augustinus Hiponensis, Editione completa latino/italiano dell'Opera omnia, Citá Nuova Editric, <http://www.augustinus.it/index2.htm> [22/08/2014].

Aldana, Francisco, Poesías castellanas completas, Ed. de José Lara Garrido, México, Cátedra, 1985 (Rei México; Letras Hispánicas, 223).

Benassy Berling, Marie-Cécile, Humanismo y religión en Sor Juana Inés de la Cruz, México, Universidad Nacional Autónoma de México, 1983.

Boecio, Tratados teológicos y la Consolación de la filosofía, Introd. de Ramón Xirau, México, Conaculta, 1989.

Brunus Nolanus, Iordanus, De umbris idearum, Parisiis, Aegidium Gorginum, 1582.

Bruno, Giordano, Los heroicos furores, Introd., trad. y notas de Ma. Rosario González Prada, Madrid, Tecnos, 1987 (Metrópolis).

Bruno, Giordano, Las sombras de las ideas, Trad. de Jordi Raventós, pról. de Eduardo Vinatea, Madrid, Siruela, 2009 (Biblioteca de Ensayos, 65).

Burnet, John, Early Greek Philosophy, a partir de la 3a. ed., London, A \& C Black Ltd., 1920, <http://classicpersuasion.org/pw/burnet/index.htm> [22/08/2014].

Burns, Dylan, «The Caldean Oracles of Zoroaster, Hekate's Couch and the Platonic Orientalism in Psellos and Plethon», Aries, 6, 2, abr, 2006, pp. 158-179.

Cassirer, Ernst, The Individual and the Cosmos in Renaissance Philosophy, Trad. de Mario Domandi, Oxford, Basil Blackwell, 1963. 
Copenhaver, Brian, Renaissance Philosophy (History of Western Philosophy), Oxford, Oxford University Press, 1992.

Egido, Aurora, «La silva barroca andaluza», Criticón, 46, 1989, pp. 5-39.

Farinella, Alessandro G., «Giordano Bruno: Neoplatonism and the Wheel of Memory in the De Umbris Idearum», Renaissance Quarterly, 55, 2002, pp. 596-624.

Ficino, Marsilio, De amore. Comentario a «El Banquete» de Platón, Rocío de la Villa Ardura (ed.), Madrid, Tecnos, 3ª. ed., 1994 (Metrópolis).

Hamilton, Albert Charles, The Spenser Encyclopedia, Toronto, University of Toronto Press, 1990.

Hudson, Nancy J., Becoming God: The Doctrine of Theosis in Nicholas of Cusa, Washington, The Catholic University of America Press, 2007.

Juana Inés de la Cruz, Sor, Obras completas, vol. I, ed., pról. y notas de Alfonso Méndez Plancarte, México, Fondo de Cultura Económica, 1951; vol. IV, ed. de Alberto G. Salceda, México, Fondo de Cultura Económica, 1957.

Juana Inés de la Cruz, Sor, Primero sueño. Texto con introducción y notas. Nota preliminar de Gerardo Moldenhauer, Introd. de Karl Vossler y Ludwig Pfandl, notas de Karl Vossler, Buenos Aires, Imprenta Universitaria, 1953.

Kircher, Athanasius, Magnes, sive de arte magnética opus tripartitum, Coloniae Agrippinae, lodocum Kalcoven, 1643.

Kircher, Athanasius, Obeliscus Pamphilius, Roma, Ludovici Grignani, 1650.

Kircher, Athanasius, Oedipus Aegyptiacus, t. II, Roma, 1653.

Kircher, Athanasius, Obelisci aegyptiacus nuper... efossi interpretatio hieroglyphica, Roma, 1666.

Nicolás de Cusa, Opera, Basilea, Henricpetrina, 1565.

Nicolás de Cusa, De ludo globi o El juego de las esferas, Introd., trad. y notas de J. Rafael Martínez E., México, Universidad Nacional Autónoma de México, 1994a (Mathema).

Nicolás de Cusa, «De filiatione Dei (On Being the Son of God)» $\mathrm{y}$ «De venatione sapientiae (On the Pursuit of Wisdom)», en Jasper Hopkins (trad., del texto latino contenido en Nicolás de Cusa, Opera Omnia, vol. IV, Hamburg, Felix Meiner Verlag, 1959), en A Miscellany on Nicholas of Cusa, Minneapolis, The Arthur J. Banning Press, 1994b.

Nicolás de Cusa, De coniecturis, edición digitalizada a cargo de Burkhard Mojsisch, de la Bibliotheca Augustana, 2007, a partir de la edición de Opera omnia, vol. III, Hamburgo, I. Koch/C. Bormann I. G., 1972. El incunable es de 1441-1442 $<$ http://www.fh-augsburg.de/ Harsch/Chronologia/Lspost15/Cusa/cus_intr. $\mathrm{html}>[22 / 08 / 2014]$. 
Nicolás de Cusa, Acerca de la docta ignorancia. Libro I: Lo máximo absoluto (edición bilingüe), Introd., trad. y notas de Jorge M. Machetta y Claudia D'Amico, Buenos Aires, Biblos, 2003 (Presencias Medievales).

Olivares Zorrilla, Rocío, La figura del mundo en «El sueño», de Sor Juana Inés de la Cruz, tesis doctoral en Letras, Universidad Nacional Autónoma de México, Facultad de Filosofía y Letras, 1998a, <http://dialnet.unirioja.es/servlet/ tesis?codigo $=21810>[22 / 08 / 2014]$.

Olivares Zorrilla, Rocío, «Los tópicos del sueño y del microcosmos: la tradición de Sor Juana», en Sor Juana Inés de la Cruz y las vicisitudes de la crítica, Ed. de José Pascual Buxó, México, Instituto de Investigaciones Bibliográficas, UNAM, 1998b (Serie Estudios de Cultura Literaria Novohispana), pp. 179-211.

Olivares Zorrilla, Rocío, «La poética matemática en Sor Juana», en La producción simbólica en la América Colonial, Ed. y pról. de José Pascual Buxó, México, UNAM, Instituto de Investigaciones Bibliográficas (Serie Estudios de Cultura Literaria Novohispana), 2001, pp. 145-160.

Olivares Zorrilla, Rocío, «Sor Juana y la tradición mística», en Literatura Hispanoamericana, de Actas del XIV Congreso de la Asociación Internacional de Hispanistas, Tomo IV, Edición de Isaías Lerner, Robert Nival y Alejandro Alonso, New York, Juan de la Cuesta, 2004a (Hispanic Monographs), pp. 487-494.

Olivares Zorrilla, Rocío, «Tradición de la poesía visionaria y emblemática mística y moral en el Primero sueño, de Sor Juana», en Florilegio de estudios de Emblemática. A Florilegium of Studies on Emblematics. Actas del VI Congreso Internacional de Emblemática de The Society for Emblem Studies. Proceedings of the 6th International Conference of the Society for Emblem Studies, Ed. de Sagrario López Poza, La Coruña, Sociedad de Cultura Valle Inclán, 2004b, pp. 553-558.

Olivares Zorrilla, Rocío, «Juan Eusebio Nieremberg y Sor Juana Inés de la Cruz», en Arellano, Ignacio y Robin Rice (eds.), Doctrina y diversión en la cultura española y novohispana, Madrid, Iberoamericana, 2009, pp. 149-165.

Olivares Zorrilla, Rocío, «Apologética, mítica y mística en El Divino Narciso», en Espéculo. Revista de estudios literarios. Universidad Complutense de Madrid, núm. 46, nov 2010 a feb 2011, <http://www.ucm.es/info/especulo/numero46/ divinar.html> [22/08/2014].

Paz, Octavio, Sor Juana Inés de la Cruz o las trampas de la fe, México, Fondo de Cultura Económica, 1982.

Plotino, Enéada cuarta, José Antonio Mínguez (trad.), Madrid, Aguilar, 3a ed., 1980 (Iniciación Filosófica).

Proclus, Commentaires sur le Timée, vol. 3, trad. et notes de A. J. Festugière, Paris, Vrin, 1967. 
Pseudo Dionisio Areopagita, Obras completas. Teología mística, Madrid, Biblioteca de Autores Cristianos, 1995.

Sabat de Rivers, Georgina, El sueño de Sor Juana Inés de la Cruz: tradiciones literarias y originalidad, London, Tamesis, 1977 a.

Sabat de Rivers, Georgina, "Trillo y Figueroa y El sueño de Sor Juana», en Actas del Quinto Congreso Internacional de Hispanistas, Universidad de Bordeaux, $1977 n$.

Salazar y Torres, Agustín de, Cythara de Apolo, Primera parte, Madrid, Francisco Sanz, 1681.

Wind, Edgar, Los misterios paganos del Renacimiento, Barcelona, Barral Editores, 1972 (Biblioteca de las Historias, Serie Iconológica, 1). 
